\title{
IMPACT OF MECONIUM STAINED AMNIOTIC FLUID ON EARLY NEONATAL OUTCOME
}

Uday Rajput ${ }^{1}$, Anu Jain²

\section{HOW TO CITE THIS ARTICLE:}

Uday Rajput, Anu Jain. "Impact of meconium stained amniotic fluid on early neonatal outcome". Journal of Evolution of Medical and Dental Scienc es 2013; Vol. 2, Issue 45, November 11; Page: 8788-8794.

ABSTRACT: OBJECTIVE: To find out the incidence, neonatal outcome and associated maternal antepartum \& intrapartum risk factors of meconium stained amniotic fluid (MSAF). DESIGN: Prospective Study. SETTINGS: Neonatal Unit of Hospital and PNC Ward. SUBJECTS \& METHODS: Prospective Study was conducted including 100 babies born with meconium stained amniotic fluid who are admitted in NICU and with mother in PNC ward in a period of six months (April 2012October 2012) excluding those who born with congenital abnormalities. Detail history of babies and mother with MSAF noted with emphasis on antepartum and intrapartum risk factors and outcome in terms of morbidity and mortality. RESULTS: Incidence of MSAF in the study was 8. 98\%. Out of 100, 24 babies were admitted to NICU with most common indications being birth asphyxia (16\%) and Meconium Aspiration Syndrome (MAS) (6\%). Majority babies were delivered through thin Meconium Stained Liquor (MSL) (44\%) followed by thick (35\%) and moderate (21\%). Total number of deaths were 9 and all these babies had thick meconium with severe birth asphyxia. Ninety one babies were born at $>37$ weeks of gestation and 57 had birth weight over $2.5 \mathrm{Kg}$. Nineteen percent were non vigorous requiring tracheal suctioning and positive pressure ventilation at birth. Common mode of delivery was emergency Cesarean in 83\% patients. Common maternal and fetal risk factors were fetal distress (30\%) followed by Oligohydramnios (30\%), Pregnancy induced hypertension (PIH) (24\%), anemia (14\%), severe anemia (5\%), Antepartum hemorrhage (4\%) and Antepartum eclampsia (4\%). CONCLUSIONS: Oligohydramnios, PIH, anemia and fetal distress were common antenatal and intranatal factors associated with MSAF. Major morbidity and indication for NICU admission was Birth asphyxia and non vigorous babies. Mortality rate was $9 \%$ which is commonly associated with thick meconium and severe birth asphyxia.

KEY WORDS: Meconium stained amniotic fluid, meconium aspiration syndrome, early neonatal outcome

INTRODUCTION: Meconium Aspiration Syndrome (MAS) continues to be threat to many newborns throughout the world with a case fatality rate of $5 \%$ (as much as $40 \%$ ), in addition to short and long term pulmonary and neurodevelopmental sequelae(1)

India has the unfortunate distinction of claiming more than a quarter of the total newborn deaths in the world (2). One such attribute is meconium stained amniotic fluid (MSAF) which complicates delivery in approximately $8 \%$ to $15 \%$ of live births (3). In a large series, MSAF was found in $12 \%$ of $1,77,000$ live births. MAS occurs in 1-3\% of all cases of MSAF and in $10-30 \%$ of neonates with meconium aspiration (4).

Various risk factors are associated with increased mortality and morbidity in MAS like postterm babies, primipara and grand multipara, unbooked mothers, mother s with toxemia of pregnancy or prolonged rupture of the membranes, infants with moderate or severe birth asphyxia and 
operative deliveries ${ }^{(5)}$. Thick MSAF is more likely with maternal age $>30$, postdated pregnancy, and fetal distress (8)

With facilities like continuous fetal heart monitoring, fetal Doppler, scalp pH estimations, the degree of fetal compromise can be evaluated early (6). But, in a developing country like ours, where most peripheral centers are devoid of facilities for managing high risk deliveries or giving essential newborn care and over $60 \%$ births are domiciliary, the role of anticipation and timely referral assumes great importance. It can not only reduce neonatal morbidity and mortality but also has maternal implications (8). Hence, the present study was undertaken to detect the antenatal and intrapartum clinical variables in mother as well as outcome of MSAF in early neonatal period.

SUBJECTS AND METHODS: A prospective observational study was carried out over a 6 month period from April 2012 to October 2012 in the Neonatal unit and PNC Ward of Government Medical College and Hospital, Miraj.

Hundred neonates delivered through meconium stained amniotic fluid consecutively which includes inborn as well as outborn neonates admitted to NICU \& those with mother in PNC ward were included in the study. Babies born with MSAF who were having significant life threatening congenital abnormalities were excluded from this study.

Detail history of babies delivered with MSAF were noted with special emphasis on factors like need of resuscitation, vigorous, non-vigorous babies, need for NICU admission, consistency of meconium etc. and detail history of mothers was taken with emphasis on antepartum and intrapartum risk factors like any medical disease to mother, obstetric complications, cord problems, fetal distress etc.

Consistency of meconium was divided into thin, thick and moderate. Thick meconium was characterised by opaque and deep green coloured liquor whereas thin meconium was characterised by translucent and light yellow green coloured amniotic fluid and while opalescent liquor with colour in between deep gr een and light yellow green represent moderate meconium.

Morbidity of neonates were noted with emphasis on Meconium Aspiration Syndrome (MAS), Respiratory distress, hospitalization duration, time of initiation of feed, birth asphyxia, ventilatory requirement, sepsis, growth retardation, gestational age, weight, etc. Babies were followed up till the time of discharge and mortality was noted.

RESULTS: During the study period, a total of 1113 deliveries were conducted. Of these 100 (8. 98\%) had meconium stained amniotic fluid. Forty four percent had thin meconium stained liquor, 35\% had thick while $21 \%$ had moderately meconium stained liquor.

Incidence was found to be more in male neonates (55\%). The male-female ratio was 1.2:1. MSAF was greater in term deliveries (91\%) whereas in preterm deliveries, thick meconium found in majority cases (55.6\%). A total of 53\% babies born through MSAF had weight between between 2.5 and $3.5 \mathrm{~kg}$ followed by $40 \%$ babies having low birth weight (1.5 -2.5 kg). Mothers having low birth and very low birth weight babies had thick meconium predominantly (Refer Table. I)

Common mode of delivery was Caesarean Section (83\%) (Refer Table II) MSAF was more common in pregnancies associated with antenatal complications like Oligohydramnios (30\%), pregnancy induced hypertension (24\%), anemia (14\%), antepartum eclampsia (4\%) and antepartum hemorrhage (4\%). During labour, MSAF was more frequent in pregnancies with fetal 
distress (30\%). Postdate pregnancy was found to be major risk factor with an incidence of 33\% (Refer Table. III)

Twenty four percent babies were admitted to NICU in which 21 were admitted at birth and 3 babies after 24 hours. Thick meconium was an important indicator of NICU admission with an incidence of 58.3\%. Mean NICU stay were 4 days. Mortality rate was $9 \%$ in which 8 babies (88.8\%) born in thick meconium group and 1 in thin meconium group (Refer Table. IV). Analysis of neonatal outcome shows that birth asphyxia was the main cause for NICU admission. Meconium aspiration syndrome developed in 6\% of MSAF babies with frequency higher with thick meconium (83.3\%) (Refer Table. V).

Among 100 babies, $81 \%$ were vigorous. Thick meconium was more common in non vigorous babies (63.15\%) (Refer Table. VI). Resuscitation modalities were stimulation alone in 17\%, positive pressure ventilation in $13 \%$. Chest compression given to $6 \%$ babies and adrenaline to $8 \%$. Resuscitation measures were performed predominantly in neonates born through thick MSAF (Refer Table. VII).

DISCUSSION: Meconium stained amniotic fluid (MSAF) is a frequent occurrence seen in obstetric and neonatal practice. In present study, the incidence of MSAF was 8.98\%. Comparable results were noted by other studies. $(6,10,11,16)$

High prevalence of MSAF seen in male neonates with an incidence of 55\%. Similar results were noted by National Neonatal Perinatal Database 2002-2003 (16) and Vineetagupta et al (4). Regarding gestational age, this study shows that 33\% women were postdated which is consistent with NekeAkhtar et al (7), Sankhyan Naveen et al (8) and Shaikh et al (9). The hormone motilin is secreted in ever increasing quantities by the fetus as gestation advances and most meconium discharges are said to occur in postdate gestations, because the motilin levels are highest then (8). In the present study, 91\% babies were term. Finding was comparable with other studies $(11,13) \mathrm{A}$. Narang et al concludes that majority babies were good weight with $76 \%$ weighing more than $2.5 \mathrm{Kg}$, $6.4 \%$ below $1.5 \mathrm{Kg}$ and only 5.5\% with MSAF were weighing less than $2 \mathrm{~kg}$ (11). In our study, 53\% babies had birth weight between $2.5 \mathrm{Kg}$ and $3.5 \mathrm{Kg}$ and $40 \%$ had low birth weight. Some studies reported its higher prevalence in pregnancies associated with fetal growth retardation (4) but, in utero passage of meconium in premature infants is uncommon.

Mode of delivery is significantly affected by meconium staining of liquor and it is stated that Caesarean sections were performed twice as frequently in women presenting with MSAF (9). Incidence of Cesarean section was 83\% in our study. Similar result observed by Shaikh et al in 2010 (9).

Of the various antenatal complications, Oligohydramnios, Pregnancy induced hypertension and Anemia had shown high prevalence in association with MSAF with an incidence of 30\%, 24\% and $14 \%$ respectively. In this study, incidence of oligohydramnios and PIH was higher than those reported by other authors $(8,12,16)$. As this study had been conducted in a tertiary center where a large number of complicated pregnancies including oligohydramnios and PIH are referred, their incidence was higher. During labour, fetal distress was high in pregnancies with MSAF with an incidence of $30 \%$. Vineeta gupta et al also showed a high incidence of fetal distress (4).

Thick meconium is associated with more admissions to NICU as concluded by Nirmala Duhan et al (6) which was also seen in the present study as it is more often associated with birth asphyxia, 
MAS and other neonatal outcomes as compared to thin meconium. Nekeakhtar et al observed that birth asphyxia is main cause for NICU admission in neonates associated with meconium passage in utero (7). Our study confirms this observation showing $16 \%$ incidence.

This study showed that $19 \%$ neonates were non vigorous associated predominantly with thick meconium (63.15\%). These babies require immediate suctioning. If the infant is vigorous, endotracheal suction is not recommended, because it may cause harm and does not improve the outcome (15). Incidence of neonatal death associated with MSAF varies from $4.9 \%$ in study of Vineetagupta et al (4) to 7\% in Takroni et al study (14). In the present study, it was 9\%.

In the end it is concluded that the knowledge of antenatal and intrapartum factors associated with MSAF provides easy prediction of adverse outcomes in neonates who can be managed by optimal timely intervention in order to avoid severe asphyxia and meconium aspiration and its complications.

\section{KEY MESSAGES:}

1. Antenatal and intranatal factors associated with MSAF provide a way of early identification of high risk cases in resource poor setup where facilities like electronic fetal monitoring are not available.

2. Higher incidence of birth asphyxia, Meconium Aspiration Syndrome and other morbidities associated with thick meconium compared to thin and moderate meconium.

CONTRIBUTORS: UCR was involved in designing the study and preparation of the manuscript. ATJ was involved in conduction of study and manuscript writing.

Funding-None

Competing interests-None stated

ACKNOWLEDGEMENT: The authors thanks Dr. N. G Harekar, Dean, and Dr. S. S. Wagh, Head, Department of Pediatrics, Government Medical College and Hospital, Miraj for allowing us to conduct the study.

\section{REFERENCES:}

1. YurdakokM. Meconium aspiration syndrome:do we know? Turk J Pediatr. 2011 Mar-Apr;53 (2):121-9.

2. Dhimant Parekh, Neonatal Care in India:Raising a generation by raising awareness[0nline] 2010 Jan 5[cited 2012 Jan 4]. Available from URL : http://www. The better india. com/1107/

3. John P. Cloherty, Eric C. Eichenwald, Ann R. Stark. Manual of Neonatal Care, 6th ed. New Delhi (India) :Wolters Kluwer:2008. p. 9, 28-34, 323-331, 383-386, 358-364.

4. VineetaGupta, B. D. Bhatia and O. P. Mishra. Meconium stained amniotic fluid: antenatal, intrapartum and neonatal attributes. Indian Pediatr. 1996 Apr;33 (4) :293-7.

5. BhaskarSH, KarthikayenG, BhatBV, BhatiaBD. Antenatal risk factors and neonatal outcome in meconium aspiration syndrome. Indian J Matern Child Health. 1997 Jan-Mar;8 (1) :9-12.

6. Nirmala Duhan, Anshu Paul, Urmila Duhan, Anjali. Meconium staining of amniotic fluid-a poor indicator of fetal compromise. Jk Science 2010 Oct-Dec;12 (4) :184-186. 
7. Neke Akhtar, Fazilatunnesa, Sharmeen Yasmeen. Mode of delivery and Fetal outcome in meconium stained amniotic fluid (MSAF) in DMCH. 2006.

8. Sankhyan Naveen, Sharma Vijay Kumar, SarinRitu, Pathania Kushla. Predictors of meconium stained amniotic fluid: a possible strategy to reduce neonatal morbidity and mortality. J ObstetGynecol 2006 Nov-Dec;56 (6) :514-517.

9. Erum Majid Shaikh, Sadaf Mehmood, Shaikh Zyed, Majid Ahmed Shaikh. Neonatal outcome in meconium stained amniotic fluid-one year experience. J Pak Med Assoc. 2010 Sep;60 (9) :7114.

10. Alchalabi H, Abu-Heija AT, El-Sunna E, Zayed F, Badria LF, Obeidat A. Meconium-stained amniotic fluid in term pregnancies-a clinical view. J Obstet Gynaecol 1999 May;19 (3) :262-4.

11. Narang A, Nair PM, Bhakoo ON, Vashisht K. Management of meconium stained amniotic fluid: a team approach. Indian Pediatr 1993 Jan;30 (1) :9-13.

12. Fischer C, Rybakowski C, Ferdynus C, Sagot P, Gouyon JB. A Population-Based Study of Meconium Aspiration Syndrome in Neonates Born between 37 and 43 Weeks of Gestation. Int J Pediatr 2012;2012:321545. Epub 2011 Nov 30.

13. Espinheira MC, Grilo M, Rocha G, Guedes B, Guimarães H. Meconium aspiration syndrome - the experience of a tertiary center. Rev Port Pneumol 2011 Mar-Apr;17 (2) :71-6.

14. Al Takroni AM, Parvathi CK, Mendis KB, Hassan S, Reddy I, KudairHA. Selective tracheal suctioning to prevent meconium aspiration syndrome. Int J Gynaecol Obstet 1998 Dec;63 (3):259-63.

15. Indu A Chadha. Neonatal resuscitation: Current issues. Indian J Anaesth. 2010 Sep-Oct; 54 (5): 428-438.

16. Report of the National Neonatal Perinatal Database. Report 2002-2003. NNPD Network. 2012 July; Available from URL: http://www. newbornwhocc. org/pdf/nnpd_report_2002-03. PDF

\begin{tabular}{|c|c|c|c|}
\hline CHARACTERISTICS & $\begin{array}{l}\text { THIN* }^{*} \\
(n=44)\end{array}$ & $\begin{array}{l}\text { THICK* } \\
(n=35)\end{array}$ & $\begin{array}{c}\text { MODERATE* } \\
(n=21)\end{array}$ \\
\hline \multicolumn{4}{|l|}{ SEX (\%) } \\
\hline Male (55) & $23(41.8 \%)$ & $20(36.4 \%)$ & $12(21.8 \%)$ \\
\hline Female (45) & $21(46.66 \%)$ & $15(33.3 \%)$ & $9(20 \%)$ \\
\hline \multicolumn{4}{|l|}{ GESTATION WEEKS (\%) } \\
\hline$<37(9)$ & $2(22.2 \%)$ & $5(55.6 \%)$ & $2(22.2 \%)$ \\
\hline $37-41(91)$ & $42(46.15 \%)$ & $30(32.9 \%)$ & $19(20.8 \%)$ \\
\hline$>42$ & - & - & - \\
\hline \multicolumn{4}{|c|}{ BIRTH WEIGHT (GMS) (\%) } \\
\hline$<1500(3)$ & - & 3 & - \\
\hline $1501-2500(40)$ & $16(40 \%)$ & $17(42.5 \%)$ & $7(17.5 \%)$ \\
\hline $2501-3500(53)$ & $27(50.9 \%)$ & $15(28.3 \%)$ & $11(20.7 \%)$ \\
\hline$>3500(4)$ & $1(25 \%)$ & - & $3(75 \%)$ \\
\hline
\end{tabular}

${ }^{*}$ Consistency of meconium 


\section{ORIGINAL ARTICLE}

\begin{tabular}{|c|c|c|c|}
\hline MODE OF DELIVERY (\%) & $\begin{array}{c}\text { THIN } \\
(\mathbf{n = 4 4 )}\end{array}$ & $\begin{array}{c}\text { THICK } \\
(\mathbf{n = 3 5 )}\end{array}$ & $\begin{array}{c}\text { MODERATE } \\
(\mathbf{n = 2 1 )}\end{array}$ \\
\hline CESAREAN SECTION (83) & $32(38.5 \%)$ & $31(37.3 \%)$ & $20(24.09 \%)$ \\
\hline VAGINAL (17) & $12(70.5 \%)$ & $4(23.5 \%)$ & $1(5.88 \%)$ \\
\hline
\end{tabular}

Table 2. Mode of delivery and Meconium staining of liquor

\begin{tabular}{|c|c|c|c|}
\hline VARIABLES ASSOCIATED WITHMSAF & $\begin{array}{c}\text { THIN } \\
(n=44)\end{array}$ & $\begin{array}{l}\text { THICK } \\
(n=35)\end{array}$ & $\begin{array}{c}\text { MODERATE } \\
(n=21)\end{array}$ \\
\hline \multicolumn{4}{|l|}{ ANTEPARTUM FACTORS } \\
\hline APH (4) & $2(50 \%)$ & $2(50 \%)$ & - \\
\hline PIH (24) & $11(45.8 \%)$ & $7(29.16 \%)$ & $6(25 \%)$ \\
\hline APE (4) & $1(25 \%)$ & $3(75 \%)$ & - \\
\hline OLIGOHYDRAMNIOS (30) & $11(36.6 \%)$ & $16(53.3 \%)$ & $3(10 \%)$ \\
\hline POLYHYDRAMNIOS (4) & $3(75 \%)$ & - & $1(25 \%)$ \\
\hline ANEMIA (14) & $4(28.57 \%)$ & $5(35.71 \%)$ & $5(35.71 \%)$ \\
\hline SEVERE ANEMIA (5) & $3(60 \%)$ & $1(20 \%)$ & $1(20 \%)$ \\
\hline HEPATITIS (1) & - & - & 1 \\
\hline JAUNDICE (1) & - & - & 1 \\
\hline RVD (2) & 2 & - & - \\
\hline \multicolumn{4}{|l|}{ INTRAPARTUM FACTORS } \\
\hline FETAL DISTRESS (FD) (30) & $9(30 \%)$ & $14(46.6 \%)$ & $7(23.3 \%)$ \\
\hline (1) FD ALONE (20) & $6(30 \%)$ & $11(55 \%)$ & $3(15 \%)$ \\
\hline (2) FD WITH OL (3) & $1(33.3 \%)$ & $1(33.3 \%)$ & $1(33.3 \%)$ \\
\hline (3) FD WITH NPL (1) & - & 1 & - \\
\hline (4) FD WITH CORD PROBLEMS (6) & $2(33.3 \%)$ & $1(16.6 \%)$ & $3(50 \%)$ \\
\hline NON PROGRESS OF LABOR (1) & - & 1 & - \\
\hline OBSTRUCTED LABOR (6) & $2(33.3 \%)$ & $4(66.6 \%)$ & - \\
\hline CORD PROBLEMS (6) & 6 & - & - \\
\hline PROM (8) & $4(50 \%)$ & $3(37.5 \%)$ & $1(12.5 \%)$ \\
\hline POSTDATE PREGNANCY (33) & $16(48.48 \%)$ & $8(24.2 \%)$ & $9(27.2 \%)$ \\
\hline
\end{tabular}

Table 3. Antenatal and Intrapartum factors associated with MSAF

\begin{tabular}{|c|c|c|c|}
\hline & $\begin{array}{c}\text { THIN } \\
(\mathbf{n = 4 4 )}\end{array}$ & $\begin{array}{c}\text { THICK } \\
(\mathbf{n = 3 5 )}\end{array}$ & $\begin{array}{c}\text { MODERATE } \\
(\mathbf{n = 2 1 )}\end{array}$ \\
\hline ADMISSION TO NICU (24) & $7(29.16 \%)$ & $14(58.3 \%)$ & $3(12.5 \%)$ \\
\hline ADMISSION AT BIRTH (21) & $5(23.8 \%)$ & $14(66.66 \%)$ & $2(9.52 \%)$ \\
\hline $\begin{array}{c}\text { ADMISSION AFTER } 24 \\
\text { HOURS (3) }\end{array}$ & $2(66.66 \%)$ & - & $1(33.33 \%)$ \\
\hline DEATH (9) & $1(11.1 \%)$ & $8(88.8 \%)$ & - \\
\hline DISCHARGE (15) & $6(40 \%)$ & $6(40 \%)$ & $3(20 \%)$ \\
\hline
\end{tabular}

Table 4. Admission to NICU and Neonatal mortality 


\begin{tabular}{|c|c|c|c|}
\hline MORBIDITY (\%) & $\begin{array}{c}\text { THIN } \\
(\mathbf{n = 4 4 )}\end{array}$ & $\begin{array}{c}\text { THICK } \\
(\mathbf{n = 3 5})\end{array}$ & $\begin{array}{c}\text { MODERATE } \\
\mathbf{( n = 2 1 )}\end{array}$ \\
\hline BIRTH ASPHYXIA (16) & $4(25 \%)$ & $10(62.5 \%)$ & $2(12.5 \%)$ \\
\hline MAS (6) & $1(16.6 \%)$ & $5(83.3 \%)$ & - \\
\hline HIE (3) & $1(33.3 \%)$ & $1(33.3 \%)$ & $1(33.3 \%)$ \\
\hline PULMONARY HEMORHAGE (1) & - & 1 & - \\
\hline RDS (2) & - & 2 & - \\
\hline SEPTICEMIA (4) & - & 4 & - \\
\hline MDS (2) & - & 2 & - \\
\hline
\end{tabular}

Table 5. Outcome of babies born through meconium stainedamniotic fluid

\begin{tabular}{|c|c|c|c|}
\hline $\begin{array}{c}\text { CONDITION OF } \\
\text { BABY (\%) }\end{array}$ & $\begin{array}{c}\text { THIN } \\
(\mathbf{n = 4 4 )}\end{array}$ & $\begin{array}{c}\text { THICK } \\
\mathbf{( n = 3 5 )}\end{array}$ & $\begin{array}{c}\text { MODERATE } \\
(\mathbf{n = 2 1})\end{array}$ \\
\hline VIGOROUS (81) & $38(46.91 \%)$ & $23(28.39 \%)$ & $20(24.69 \%)$ \\
\hline NON VIGOROUS (19) & $6(31.5 \%)$ & $12(63.15 \%)$ & $1(5.26 \%)$ \\
\hline
\end{tabular}

Table 6. Vigorous versus Non-vigorous babies in different degrees of meconium stained liquor

\begin{tabular}{|c|c|c|c|}
\hline $\begin{array}{l}\text { MODE OF RESUSCITATION } \\
(n=19)\end{array}$ & $\begin{array}{c}\text { THIN } \\
(n=44)\end{array}$ & $\begin{array}{l}\text { THICK } \\
(n=35)\end{array}$ & $\begin{array}{l}\text { MODERATE } \\
(n=21)\end{array}$ \\
\hline STIMULATION (17) & $5(29.41 \%)$ & $11(64.7 \%)$ & $1(5.88 \%)$ \\
\hline TRACHEAL SUCTIONING (14) & $2(14.28 \%)$ & $11(78.57 \%)$ & $1(7.1 \%)$ \\
\hline PPV $(13)$ & $4(30.76 \%)$ & $8(61.53 \%)$ & $1(7.69 \%)$ \\
\hline CHEST COMPRESSION (6) & - & 6 & - \\
\hline ADRENALINE (8) & - & 8 & - \\
\hline
\end{tabular}

\section{AUTHORS:}

1. Uday Rajput

2. Anu Jain

\section{PARTI CULARS OF CONTRIBUTORS:}

1. Assistant Professor, Department of Pediatrics, Government Medical College and Hospital, Miraj.

2. Senior Resident, Department of Pediatrics, Government Medical College and Hospital, Miraj.

\section{NAME ADDRESS EMAIL ID OF THE} CORRESPONDING AUTHOR:

Dr. Uday C. Rajput, C/O, Dr. Mrs. Rajput, Prof essor \& Head, Obstetrics and Gynaecology Department, Wanless Mission Hospital, Miraj - 416410. Email - druday rajput@gmail.com

Date of Submission: 24/10/2013. Date of Peer Review: 25/10/2013. Date of Acceptance: 31/10/2013. Date of Publishing: 06/11/2013 